\title{
Impression cytology of conjunctival melanosis and melanoma
}

\author{
A D A Paridaens, A C E McCartney, O M Curling, C J Lyons, J L Hungerford
}

\section{Institute of}

Ophthalmology,

A D A Paridaens

A C E McCartney

St Bartholomew's

Hospital, Department of

Cytology

O M Curling

Department of

Ophthalmology

$\mathrm{J}$ L Hungerford

Moorfields Eye Hospital, Department of Oncology C J Lyons

Correspondence to:

Dr A CE McCartney, Institute of Ophthalmology,

$17 / 25$ Cayton Street, London ECIV 9AT.

Accepted for publication 22 August 1991
Department of Pathology

J L Hungerford

Department of Pathology,

\begin{abstract}
Impression cytology using cellulose acetate paper has been used in various ocular surface disorders as a simple non-invasive diagnostic test. To assess its value in differentiating melanocytic tumours, 24 patients with a range of pigmented lesions of the conjunctiva were examined using this technique. Cytological and histological diagnoses were compared in 23 cases. In $73 \%$ of cases impression cytology predicted the histological diagnosis by detection of superficial atypical melanocytes and their proportion relative to benign epithelial cells. This pilot study shows impression cytology to be a useful diagnostic aid in the differentiation of pigmented tumours of the bulbar conjunctiva.
\end{abstract}

The management of pigmented lesions of the conjunctiva depends on the ability to distinguish between benign, premalignant, and frankly malignant conditions. Conjunctival malignant melanoma is uncommon but potentially lethal. Most conjunctival melanomas arise in association with pre-existing primary acquired melanosis (PAM). ${ }^{2}$ It is important to recognise and monitor this precursor because of its malignant potential. Follow-up of suspicious conjunctival lesions by repeated biopsies may cause symblepharon, lid deformities, and discomfort to the patient.

Exfoliative cytology has been advocated as a

Table 1 Patient details and diagnosis

\begin{tabular}{|c|c|c|c|c|c|}
\hline Patient & $\begin{array}{l}\text { Age } \\
\text { (years) }\end{array}$ & Laterality & $\begin{array}{l}\text { Years of } \\
\text { history }\end{array}$ & $\begin{array}{l}\text { Impression }(I) / \\
\text { exfoliative }(E) \\
\text { cytology (frequency) }\end{array}$ & $\begin{array}{l}\text { Histological } \\
\text { diagnosis }\end{array}$ \\
\hline $\begin{array}{r}1 \\
2 \\
3 \\
4 \\
5 \\
6 \\
7 \\
8 \\
9 \\
10 \\
11 \\
12 \\
13 \\
14 \\
15 \\
16 \\
17 \\
18 \\
19 \\
20 \\
21 \\
22 \\
23 \\
24\end{array}$ & $\begin{array}{l}27 \\
32 \\
54 \\
75 \\
51 \\
64 \\
54 \\
58 \\
53 \\
57 \\
82 \\
31 \\
28 \\
40 \\
62 \\
89 \\
81 \\
68 \\
33 \\
58 \\
61 \\
57 \\
59 \\
42\end{array}$ & $\begin{array}{l}\text { L } \\
\text { L } \\
\text { R } \\
\text { L } \\
\text { R } \\
\text { R } \\
\text { R } \\
\text { L } \\
\text { R } \\
\text { R } \\
\text { L } \\
\text { L } \\
\text { R } \\
\text { L } \\
\text { L } \\
\text { R } \\
\text { R } \\
\text { L } \\
\text { R } \\
\text { R } \\
\text { R } \\
\text { R } \\
\text { L } \\
\text { R }\end{array}$ & $\begin{array}{c}20 \\
1 \\
3 \\
6 \\
10 \\
2 \\
12 \\
16 \\
0 \cdot 5 \\
1 \\
1 \\
18 \\
3 \\
20 \\
30 \\
? \\
3 \\
4 \\
7 \\
0 \cdot 5 \\
2 \\
0 \cdot 5 \\
0 \cdot 5 \\
2\end{array}$ & $\begin{array}{l}2 \times \mathrm{I} ; 1 \times \mathrm{E} \\
2 \times \mathrm{I} ; 2 \times \mathrm{E} \\
2 \times \mathrm{I} ; 2 \times \mathrm{E} \\
2 \times \mathrm{I} ; 1 \times \mathrm{E} \\
2 \times \mathrm{I} ; 2 \times \mathrm{E} \\
2 \times \mathrm{I} \\
2 \times \mathrm{I} \\
2 \times \mathrm{I} \\
1 \times \mathrm{I} \\
2 \times \mathrm{I} \\
1 \times \mathrm{I} \\
1 \times \mathrm{I} \\
2 \times \mathbf{I} \\
1 \times \mathbf{I} \\
1 \times \mathbf{I} \\
1 \times \mathrm{I} \\
1 \times \mathrm{I} \\
2 \times \mathbf{I} \\
2 \times \mathrm{I} \\
1 \times \mathbf{I} \\
1 \times \mathbf{I} \\
2 \times \mathrm{I} ; 2 \times \mathrm{E} \\
1 \times \mathrm{I} \\
1 \times \mathrm{I}\end{array}$ & $\begin{array}{l}\text { Naevus } \\
\text { PAM+ } \\
\text { MM (PAM+) } \\
\text { MM (PAM+) } \\
\text { MM (PAM+) } \\
\text { MM (PAM +) } \\
\text { PAM+ } \\
\text { MM (PAM +) } \\
\text { MM } \\
\text { PAM- } \\
\text { PAM+ } \\
\text { Naevus } \\
\text { PAM- } \\
\text { Naevus } \\
\text { PAM+ } \\
\text { PAM- } \\
\text { SAM } \\
\text { MM } \\
\text { PAM + PAM- } \\
\text { SAM } \\
\text { MM (PAM +) } \\
\text { PAM+ }+ \\
\text { PAM + } \\
\text { MM }\end{array}$ \\
\hline
\end{tabular}

$M M=$ malignant melanoma.

PAM $+=$ primary acquired melanosis with atypia.

PAM - = primary acquired melanosis without atypia

SAM $=$ secondary acquired melanosis.

$(\mathrm{PAM}+)=$ originating from PAM + . diagnostic and monitoring tool without significant side effects. ${ }^{3-6}$ Atypical melanocytes which have migrated to the epithelial surface can be detected by this technique which is fast, inexpensive, and less distressing to the patient than biopsy. However smears are open to misinterpretation. ${ }^{6}$ Impression cytology with the aid of a piece of cellulose acetate filter paper was first utilised as a method for 'simple conjunctival biopsy'. ${ }^{7}$ Since then the technique has been employed in the study of dry eyes, ${ }^{8}$ squamous metaplasia, ${ }^{9}$ and other surface disorders. ${ }^{8}$

The aim of this study is to assess the value of impression cytology in differentiating benign, premalignant, and malignant conjunctival tumours.

\section{Materials and methods}

Impression cytology was carried out on pigmented conjunctival lesions of 24 consecutive patients attending the Oncology Clinic at Moorfields Eye Hospital in 1990 (Table 1). In addition exfoliative cytology was performed in six of these patients prior to conjunctival biopsy under general anaesthesia. Histological specimens were obtained from all patients either after the cytological examination or at least 3 months before. None of the patients had had adjuvant therapy such as cryotherapy before cytological examination or biopsy.

Impression cytology involves pressing a $2 \times 6 \mathrm{~mm}$ cellulose acetate filter paper (Millipore) held by forceps onto the conjunctival surface with the aid of a small solid rod for 3 to 5 seconds (Fig 1). This painless procedure does not require topical anaesthesia. Tissue paper was used to absorb the inferior tear lake before sampling. After sampling the filter paper was placed in fixative solution containing glacial acetic acid, $37 \%$ formaldehyde, absolute ethyl alcohol, and distilled water. The specimens were stained with PAS/Papanicolaou, mounted on glass slides and embedded in DePeX (BDH).

For exfoliative cytology, cells were harvested by scraping the anaesthetised eye with the blunt side of a scapel blade. Subsequently they were smeared on to a glass slide and fixed with a cytological fixative aerosol spray (Comber and Son). The smears were stained with Giemsa ( $10 \%$ in buffer). Haematoxylin and eosin $(\mathrm{H}$ and E) and S-100 stained sections were prepared by the Department of Pathology, Institute of Ophthalmology for histological assessment of the specimens.

All cytological specimens were examined by two independent observers. An increased nuclear to cytoplasmic ratio (in comparison with keratinocytes), an irregular nuclear chromatin pattern, the presence of large nucleoli, and the 
finding of mitoses, anisokaryosis, and melanin were regarded as cytological features of malignancy. When the relative proportion of atypical melanocytes was low the lesion was cytologically

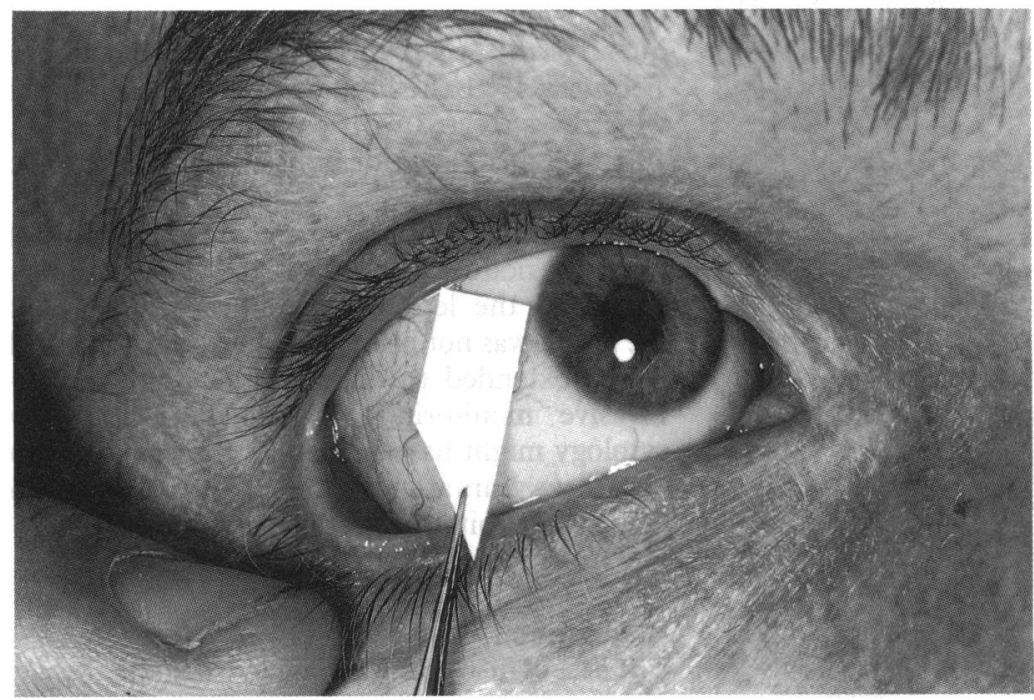

Figure 1 A cellulose acetate filter paper (Millipore) is applied to the bulhar conjunctirix of the right eye.

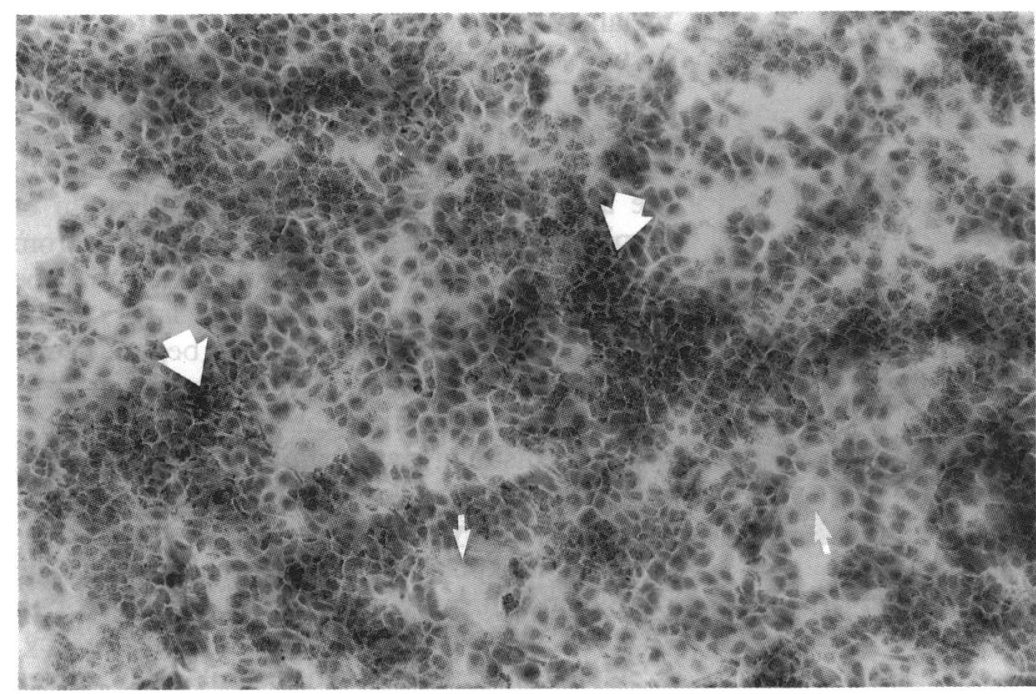

Figure 2 Abundant melanocytes (large arrows) with an increased nuclear to cytoplasmic ratio and intracellular melanin pigment granules are seen between keratinocytes (small arrows). Note the loss of goblet cells (see case report). $(\times 50$.

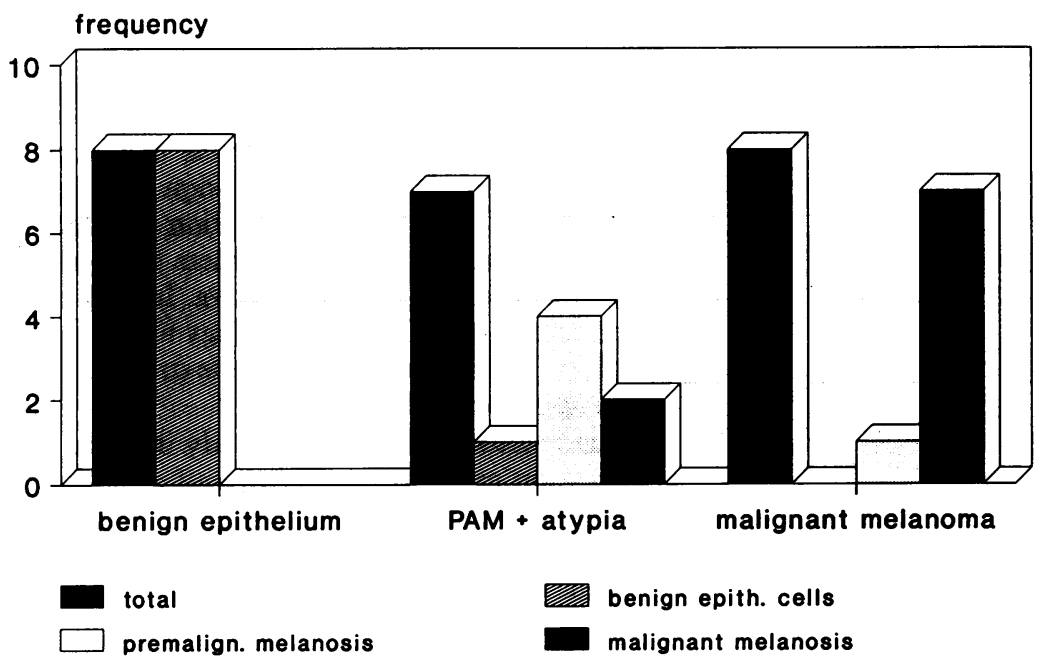

Figure 3 This histogram summarises the results of a comparison between the histological diagnosis (black bars, see horizontal axis) of 23 cases of conjunctival melanocytic lesions and the impression cytological diagnosis (striped/dotted bars, see legends). diagnosed as pre-malignant melanosis equivalent to the histological diagnosis PAM with atypia as defined by Folberg et al. ${ }^{2}$ If cancerous cells were abundant the diagnosis was malignant melanosis equivalent to malignant melanoma.

\section{Results}

In 23 out of 24 cases (Table 1) an adequate number of cells including keratinocytes, goblet cells, and inflammatory cells was harvested by impression cytology (Fig 2). In one case of melanoma in the lower fornix (case 24) access to the lesion was difficult and the adherent cells were too sparse to make a conclusive diagnosis. Fig 3 shows that impression cytology detected atypical melanocytes in seven out of eight cases of malignant melanoma diagnosed with biopsy. In one case atypical melanocytes were present only in small groups and this lesion was diagnosed as premalignant melanosis. Four out of seven cases of PAM with atypia were correctly diagnosed; in one case only benign epithelial cells were found and two other cases were classified as malignant melanosis. Thus in 11 of 15 cases $(73 \%)$ the histological diagnosis was predicted by impression cytology. Atypical melanocytes were not diagnosed in any of the cases of PAM without atypia and benign naevi.

Sufficient material was harvested by exfoliative cytology to make a cytological diagnosis in all six cases. Three out of four cases of PAM with atypia and malignant melanoma were predicted by this technique. In one case of PAM with atypia only keratinocytes and extracellular melanin were seen but no melanocytes. Neither of two benign lesions was mistaken for premalignancy or malignancy. The cytological features of individual cells were easier to recognise than in impression cytological specimens.

\section{Case report}

The use of impression cytology and exfoliative cytology of conjunctival malignant melanoma arising in an area of primary acquired melanosis is demonstrated by the following case.

A 73-year-old Caucasian woman was seen in the Oncology Clinic at Moorfields Eye Hospital in June 1988. She gave a 4 year history of gradually increasing pigmentation of the medial aspect of her right conjunctiva, caruncle, and skin of the medial canthus. On examination several flat pigmented areas were seen adjacent to a fleshy raised lesion supporting origin from PAM.

Biopsy of the caruncular element showed an inflamed cystic naevus and no evidence of frank malignancy. As a result of the biopsy she complained of double vision for 1 year. There were no further significant changes until July 1990 when multiple foci of nodular black tumour were noted in her fornices (Fig 4).

An impression cytological specimen of a nodule showed abundant atypical melanocytes (Figs 2 and 5), a finding which was confirmed by exfoliative cytology (Fig 6). The histological diagnosis in multiple incisional biopsies was predominantly epithelioid cell malignant melanoma and PAM with atypia (Fig 7). 


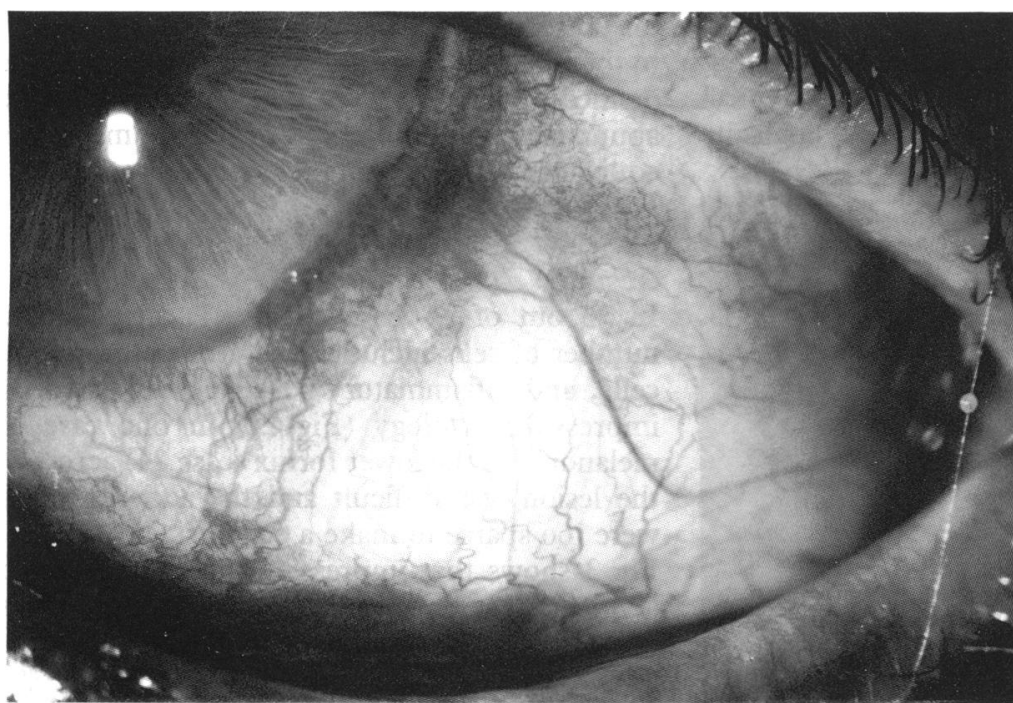

Figure 4 Flat epibulbar and caruncular melanosis and multiple foci of elevated melanocytic tumour in the lower fornix of the right eye (see case report).

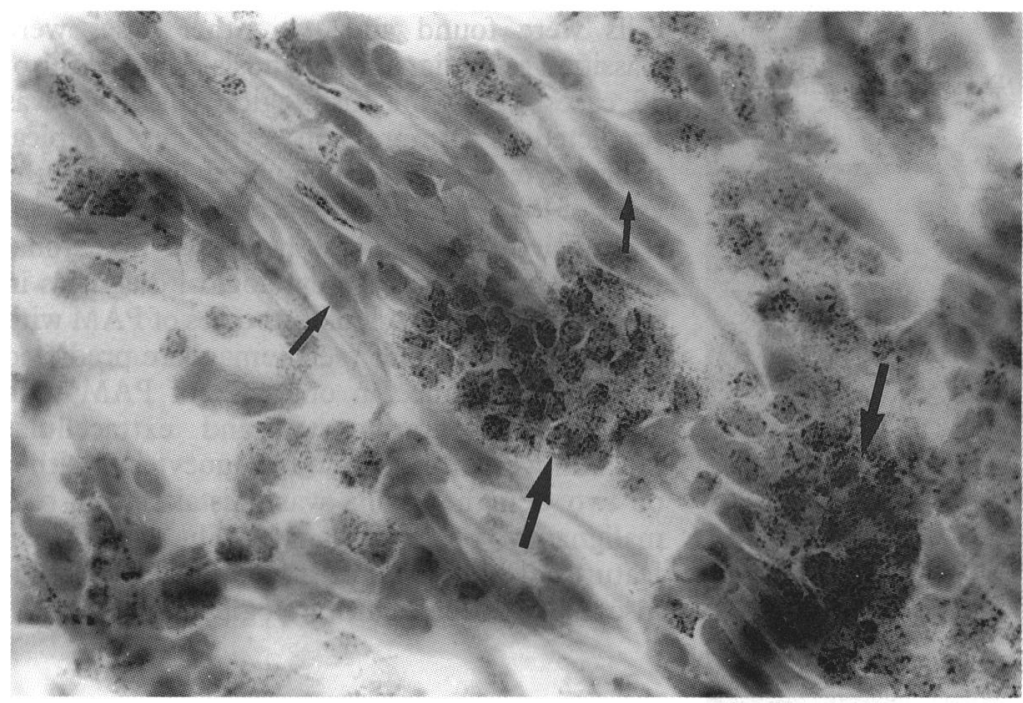

Figure 5 Impression cytological specimen (see case report) showing groups of small melanocytes (large arrows) with increased nuclear to cytoplasmic ratio, anisokaryosis, prominent eosinophilic nucleoli, and intracytoplasmic melanin pigment granules among elongated keratinocytes (small arrows). ( $\times 300$.

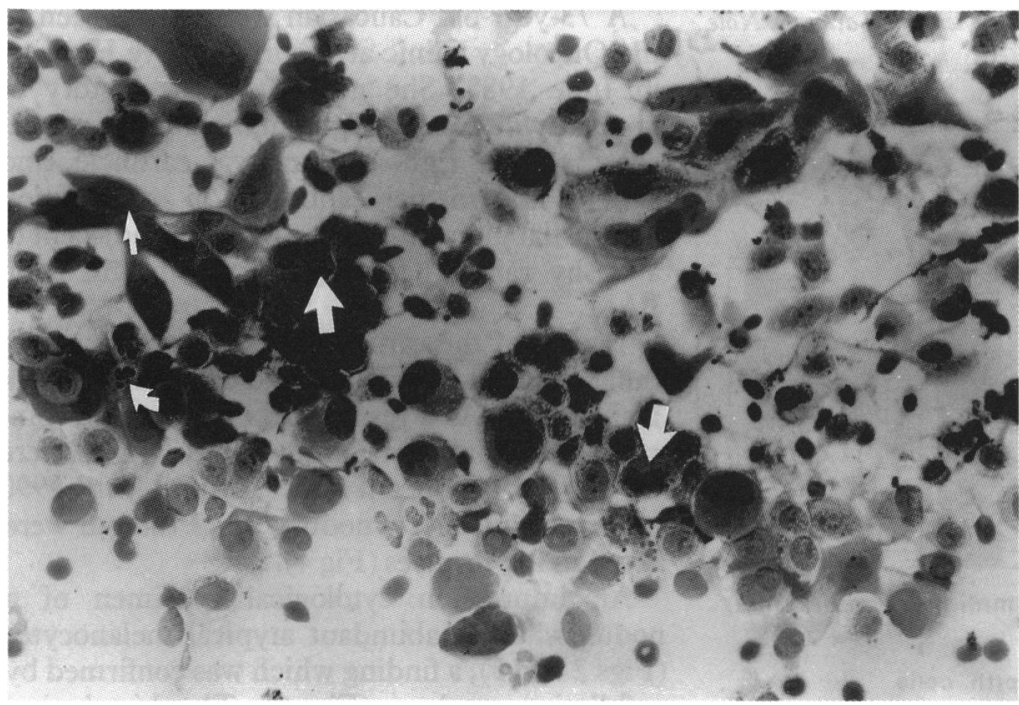

Figure 6 Scrape cytological specimen (see case report) showing keratinocytes (small arrow), inflammatory cells (curved arrow), and abundant atypical cells (large arrows) with anisokaryosis, enlarged nucleoli, intracytoplasmic melanin pigment granules, and irregular nuclear chromatin pattern. Occasionally mitotic figures are found. $(\times 300$.
Systemic tests disclosed no evidence of metastatic disease and the right orbit was exenterated in October 1990. The exenteration specimen showed tumour cells within the lacrimal common canaliculus and at the medial canthal cutaneous resection margin. Subsequently the right orbit was irradiated. In February 1991 she developed spinal metastases which was treated with palliative radiotherapy, and she died of widespread metastases some weeks later.

Comment. The initial histological diagnosis of a raised nodule in an area of flat melanosis suggested the lesion was benign. As a result the lesion was not histologically re-assessed until it had extended to the fornices. Regular noninvasive monitoring of suspicious areas by cytology might have benefited this patient, who died three years after the first biopsy and within 6 months of orbital exenteration.

\section{Discussion}

The ascent of atypical melanocytes to the surface of the conjunctival epithelium is indicative of malignancy. Folberg et $a l^{2}$ showed that PAM without atypia does not progress to frank melanoma whereas lesions with atypia tend to be incompletely excised and have a high recurrence rate.

Benign conditions such as conjunctival naevus and PAM without atypia are not associated with the ascent through conjunctival epithelium of atypical melanocytes, although benign cells from naevi growing actively in adolescence may be present in superficial conjunctival layers. ${ }^{3}$ The lack of superficial melanocytes in benign naevi, PAM without atypia, and early stages of PAM with atypia means that they can only be diagnosed by histology with cytology only providing a 'negative' diagnosis in the absence of such cells.

Impression cytology is a quick, painless, noninvasive, inexpensive outpatient technique. The histological diagnosis was predicted correctly in $73 \%$ of 15 cases of malignancy or premalignancy. Previous work ${ }^{6}$ has shown a similar percentage for exfoliative cytology. Repeated examinations may increase the sensitivity of this technique. A disadvantage in comparison with exfoliative cytology is the difficulty of focusing during microscopical examination and assessing cytological features due to the thickness of the filter paper. However the topographical distribution and relative proportion of atypical melanocytes could be better studied in impression cytology. A limitation of its use is the location of the pigmented lesion as access is a problem for tumours in the fornix and tarsal conjunctiva. In such cases examination by exfoliative cytology with a cotton wool swab and topical anaesthetic drops may be more appropriate. ${ }^{56}$

The results of the present study indicate that impression cytology could be used as a clinical monitoring tool in the follow-up of bulbar conjunctival tumours. Although a diagnostic biopsy remains necessary for determination of the origin and extent of those lesions, recurrent tumours, or suspicious areas might be biopsied less frequently thus reducing the risk of side effects and patients' discomfort. Impression cytology may 
also have a place in the investigation of other neoplastic lesions of the conjunctiva such as carcinoma in situ and squamous cell carcinoma.

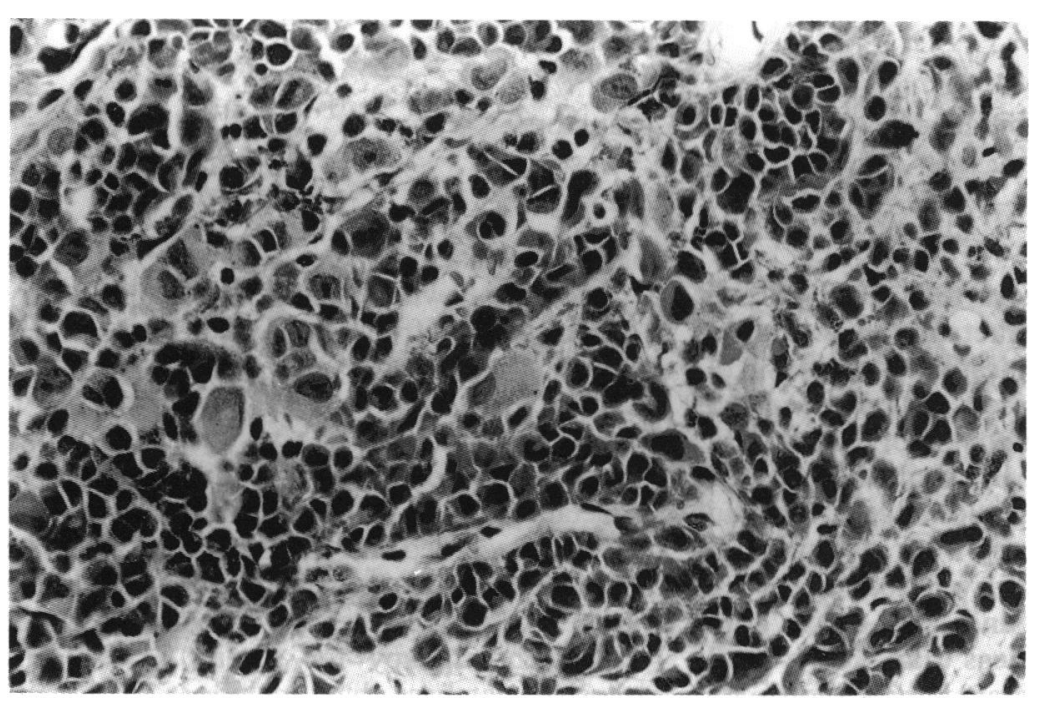

Figure 7 Histology (see case report) showing predominantly epithelioid cell malignant melanoma. $(\times 150$.
Preliminary results of this study were presented at the 162nd Meeting of the Pathological Society of Great Britain and Ireland. 'Stichting Fonds ter Bevordering van de Gezondheidszors' 'Stichting De Drie Lichten' and 'Stichting Rens-Holle', The Netherlands.

We would like to thank Mr S Bailey, FRCS for his advice and for kindly providing the filter paper and fixative, and $\mathrm{MrC}$ Elgueta for his help with the staining procedure.

1 Jakobiec FA, Rini FJ, Fraunfelder FT, Brownstein S. Cryotherapy for conjunctival primary acquired melanosis and malignant melanoma. Ophthalmology 1988; 95: 1058-70.

2 Folberg R, McLean IW, Zimmerman LE. Primary acquired melanosis of the conjunctiva. Hum Pathol 1985; 16: 129-35.

3 Gelender H, Forster RK. Papanicolaou cytology in the diagnosis and management of external ocular tumors. Arch Ophthalmol 1980; 98: 909-12.

4 Sanderson TL, Pustai CT, Shelley L, Gelender H, Alan BP. Cytologic evaluation of ocular lesions. Acta Cytol 1980; 24: Cytologic

5 Lopes Cardozo P, Oosterhuis JA, Wolff-Rouendaal D de. Exfoliative cytology in the diagnosis of conjunctival tumours. Ophthalmologica 1981; 182:157-64.

6 Wolff-Rouendaal D de. Conjunctival melanoma in the Netherlands: a clinico-pathological and follow-up study. Thesis University of Leiden, The Netherlands, 1990.

7 Egbert PR, Lauber S, Maurice DM. A simple conjunctival biopsy. Am f Ophthalmol 1977; 84: 798-801.

8 Nelson JD, Wright JC. Conjunctival goblet cell densities in ocular surface disease. Arch Ophthalmol 1984; 102: 1049-51.

9 Tseng SCG. Staging of conjunctival squamous metaplasi by impression cytology. Ophthalmology 1985; 92: 728-33. 